\title{
Discoloration of new nanohybrid composites into two different solutions (an invitro study)
}

mohammad ali wannous ( $\square$ wannousmohammad@gmail.com )

Damascus University faculty of dentistry https://orcid.org/0000-0002-9870-2611

souad ali abboud

Damascus University

Research article

Keywords: composite resins, discoloration, ormocer

Posted Date: April 2nd, 2020

DOI: https://doi.org/10.21203/rs.3.rs-19613/v1

License: (c) (i) This work is licensed under a Creative Commons Attribution 4.0 International License.

Read Full License 


\section{Abstract}

Objective: this study aimed to evaluate discoloration of two inorganic nanohybrid composite and an organic modified ceramic resin composite (ormocer) into two solution at different periods of time.

Methods: 60 discs of (admira fusion voco, tetric evoceram vivadet ivoclar , tetric N-ceram vivadent ivoclar) were prepared with dimentions of $(2 \mathrm{~mm} \times 5 \mathrm{~mm})$ and devided into three group $(A, B, C)$ Each group of 20 specimens were randomized into two subgroups, one of them were immersed in coffee and the other in cola for 1,7 , and 28 days of immersion. Color measurements were recorded every time period using Vita Easy shade compact according to the CIE L*a*b* system and results were saved for comparing .The $\Delta \mathrm{E}$ values between the study time points were calculated.

Results: Admira Fusion $\mathrm{x}$-tra showed the lowest $\Delta \mathrm{E}$ variations $(P<0.01)$ at all periods of time comparing with Tetric evoceram and Tetric $\mathrm{N}$-ceram at both solution. Coffee caused higher discoloration at all periods of time.

Conclusion: Staining beverages caused significant discolorations for all the materials tested. Coffee caused higher discoloration comparing with cola. Nanohybrid ormocer composite reported the lowest color variations.

\section{Background}

In dentistry it is a main goal to achive a natural appearance in harmony with the oral environment. Therefore, the successful selection of color is an important clinical requirement that Increases acceptance of restoration.[1] In order to preserve these aesthetic results, the restorative materials must be able to achieve Color stability, to preserve the chosen color as long as possible. Therefore Our knowledge of color science and the factors affecting it are important to achieve the best Aesthetic results of restoration .[2] Composite resin Restorations were first introduced to dentistry in the 1960s, Since then various forms have been developed to cover the various clinical indications and Composite resin became able to be used for restoring interior and posterior teeth. As the Aesthetic results are the main aspects when restoring front teeth, which requires a compatibility investigation, Excellent color stability and high surface polishing ability. Where As composite resin materials must provide high resistance to pressure, tensile strength, and Wear resistance when restoring posterior teeth .[3] The interest in cosmetic aspects has increased the use of dental composite resins and became The most common substance nowadays. This resulted in an accelerated improvement of the mechanical and cosmetic properties of resin materials. [4] In spite of this, 55\% of the resin restorations are replaced within a period of time not exceeding 5 years, and the main reason for this is the color change over time. [5] In recent years, a wide range of composites has been introduced for direct restoration in the global market .[6] In addition to traditional hybrid and nanohybrid composites of universal use, these dental systems include a sufficient number of shades and different shadow and transparency characteristics .[7] Since 1990, nanotechnology is referred to as molecular geometry, producing functional molecules and structures of 
different physical and chemical materials with dimensions ranging from 0.1 to 100 nanometers. Theoretically, nanotechnology can be used to make materials lighter, stronger, Cheaper and more accurate .[8] Nanometric fillers are very different from conventional fillers. Nanometric fillers in dental materials include: silica [9], zirconal silica [10], alumina [11], nano silicate Fibroblasts [12], titanium oxide . [13] Nanomolecules can be used as a single filler [9], or by mixing with other forms of fillers .[14] This hybrid nanosynthesis is the newest addition in the constellation of composite resins, and has become popular because of its high cosmetic properties, high wear resistance, excellent refinement and excellent material handling properties [10]. this in vitro study was to evaluate and compare the color stability of different esthetic restorative materials (tow inorganic nanoybrid composites, , and one nanoybrid ormocerbased composite) after immersioning in different staining solutions (coffee and cola).

\section{Methods}

Three nanohybrid composites (tetric N-ceram, tetric evoceram, admira fusion $\mathrm{x}$-tra) were evaluated in this study. The vita shade $\mathrm{A} 1$ was selected after testing the universal shade of admira fusion $\mathrm{x}$-tra 4 times to ensure the congruence.

\begin{tabular}{|c|c|c|c|c|}
\hline Manufacturer & Filler & Resin matrix & Classification & Composite \\
\hline \multirow[t]{2}{*}{$\begin{array}{l}\text { Voco, } \\
\text { Cuxhaven, } \\
\text { Germany }\end{array}$} & $(w 270)$ & $\begin{array}{l}100 \quad \% \\
\text { monomer with } \quad \mathrm{Crmocer} \\
\text { groups }\end{array}$ & $\begin{array}{l}\text { Nano-hybrid } \\
\text { ormocer }\end{array}$ & $\begin{array}{l}\text { Admira } \\
\text { Fusion } \\
\text { xtra }\end{array}$ \\
\hline & 76 & $\begin{array}{l}\text { BisGMA } \quad \text { TEGDMA } \\
\text { BisEMA } \\
\text { Bis-GMA, UDMA }\end{array}$ & $\begin{array}{l}\text { Nano-hybrid } \\
\text { composite }\end{array}$ & $\begin{array}{l}\text { Tetric } \\
\text { EvoCeram }\end{array}$ \\
\hline \multirow[t]{2}{*}{$\begin{array}{l}\text { Ivoclar } \\
\text { Vivadent AG, } \\
\text { Schaan, } \\
\text { Liechtenstein }\end{array}$} & 65 & $\begin{array}{l}\text { Dimethacrylates, additives, } \\
\text { catalysts, stabilizer } \\
\text { sand pigments, barium } \\
\text { glass, ytterbium }\end{array}$ & $\begin{array}{l}\text { Nano-hybrid } \\
\text { composite }\end{array}$ & Tetric \\
\hline & & $\begin{array}{l}\text { trifluoride, mixed oxide } \\
\text { and prepolymerized }\end{array}$ & & N-ceram \\
\hline $\begin{array}{l}\text { Ivoclar } \\
\text { Vivadent AG, } \\
\text { Schaan, } \\
\text { Liechtenstein }\end{array}$ & & filler (prepolymers) & & \\
\hline
\end{tabular}


A sample of 60 discs was polymerized according to manufacturers' instructions into silicone rubber rings with dimensions of $5 \mathrm{~mm}$ diameter and $2 \mathrm{~mm}$ height, to ensure the dimensional stability of all samples, rings were overfilled with the materials after being covered with mylar strip and a glass plate was placed underneath and above for 60 seconds. Then polymerized for 20 seconds on each side using a curing unit (Guilin woodpecker, Germany) using the same mode for all samples, the light was applied directly on the glass plate .No finishing or polishing was made, then the color of all discs in each group was confirmed by taking three readings using a color spectrometer Vita Easy shade compact according to the CIE $\mathrm{L}^{*} \mathrm{a} \mathrm{b}^{*}$ system. The sample was stored in distilled water for a day at a temperature of $37^{\circ} \mathrm{C}$ to ensure complete lamination and solidification. Three test group were obtained :

Group A : 20 discs of admira fusion x-ta nanohybrid ormocer composite.

Group B : 20 discs of tetric evoceram nanohybrid composite.

Group c : 20 discs of tetric N-ceram nanohybrid composite.

Each group was devided into two subgroups as follows: 10 discs of each substance immersed within the solution of coffee and 10 discs within the cola using a covered glass container to prevent evaporation of staining solutions.After 24 hours The top surface of the discs was dried with a piece of gauze and then the color changing was measured with a Spectrophotometer Vita Easy shade compact device according to the CIE L*a*b* system, where the color reading of each disk was repeated three times, and then the mean was calculated for the readings and the results were saved for comparison. Then the discs were returned to the solution at temperature of $37^{\circ} \mathrm{C}$ to repeat the same procedure of colorimetric evaluation after 7 days and 28 days.

\section{Results}

Results are summarized in Tables $(1,2,3,4,5,6)$

Table 1. showed that The value of sig was 0.000 it is smaller than 0.01 , meaning there are statistically significant differences between the mean values between Average three material in coffee after 24 hours

Table no.1 Anova Test the contrast between the average read values of all materials at time 24hours within Coffee

\begin{tabular}{|l|l|l|l|l|l|l|l|l|}
\hline & $\mathrm{N}$ & Mean & $\begin{array}{l}\text { Std. } \\
\text { Deviation }\end{array}$ & $\begin{array}{l}\text { Std. } \\
\text { Error }\end{array}$ & Minimum & Maximum & F & Sig. \\
\hline Tetric N-ceram & 10 & 4.5200 & .97502 & .30833 & 2.80 & 5.70 & 18.713 & $0.000^{* *}$ \\
\hline Tetric evoceram & 10 & 3.2100 & .39847 & .12601 & 2.50 & 3.80 & & \\
\hline $\begin{array}{l}\text { Admira fusion x- } \\
\text { tra }\end{array}$ & 10 & 2.8000 & .42947 & .13581 & 1.90 & 3.30 & & \\
\hline Total & 30 & 3.5100 & .97886 & .17872 & 1.90 & 5.70 & & \\
\hline
\end{tabular}


In Table 2. The value of sig was 0.000 it is smaller than 0.01 , meaning there are statistically significant differences between the mean values between Average three material in coffee after week of immersing.

Table no.2 Anova Test the contrast between the average read values of all materials at time week within Coffee

\begin{tabular}{|l|l|l|l|l|l|l|l|l|}
\hline & $\mathrm{N}$ & Mean & $\begin{array}{l}\text { Std. } \\
\text { Deviation }\end{array}$ & $\begin{array}{l}\text { Std. } \\
\text { Error }\end{array}$ & Minimum & Maximum & F & Sig. \\
\hline Tetric N-ceram & 10 & 9.8300 & .87693 & .27731 & 8.40 & 11.00 & 22.933 & $0.000^{* *}$ \\
\hline Tetric evoceram & 10 & 8.5100 & .41015 & .12970 & 7.75 & 9.00 & & \\
\hline $\begin{array}{l}\text { Admira fusion x- } \\
\text { tra }\end{array}$ & 10 & 8.0600 & .41218 & .13034 & 7.45 & 8.60 & & \\
\hline Total & 30 & 8.8000 & .96293 & .17581 & 7.45 & 11.00 & & \\
\hline
\end{tabular}

Table 3. The value of sig was 0.000 it is smaller than 0.01 , meaning there are statistically significant differences between the mean values between Average three material in coffe after 28 dayes.

Table no.3 Anova Test the contrast between the average read values of all materials at time 28 day within Coffee

\begin{tabular}{|l|l|l|l|l|l|l|l|l|}
\hline & $\mathrm{N}$ & Mean & $\begin{array}{l}\text { Std. } \\
\text { Deviation }\end{array}$ & $\begin{array}{l}\text { Std. } \\
\text { Error }\end{array}$ & Minimum & Maximum & F & Sig. \\
\hline Tetric N-ceram & 10 & 15.1400 & .83160 & .26297 & 13.90 & 16.60 & 21.595 & $0.000^{* *}$ \\
\hline Tetric evoceram & 10 & 13.8100 & .54047 & .17091 & 13.00 & 14.60 & & \\
\hline $\begin{array}{l}\text { Admira fusion } \\
\text { x-tra }\end{array}$ & 10 & 13.3200 & .49844 & .15762 & 12.50 & 14.20 & & \\
\hline Total & 30 & 14.0900 & .99701 & .18203 & 12.50 & 16.60 & & \\
\hline
\end{tabular}

Table 4. The value of sig was 0.001 it is smaller than 0.01 , meaning there are statistically significant differences between the mean values between Average three material in cola after 24 hours.

Table no.4 Anova Test the contrast between the average read values of all materials at time 24hours within Cola

\begin{tabular}{|l|l|l|l|l|l|l|l|l|}
\hline & $\mathrm{N}$ & Mean & $\begin{array}{l}\text { Std. } \\
\text { Deviation }\end{array}$ & $\begin{array}{l}\text { Std. } \\
\text { Error }\end{array}$ & Minimum & Maximum & F & Sig. \\
\hline Tetric N-ceram & 10 & 2.6300 & .61292 & .19382 & 1.70 & 3.60 & 9.418 & .001 \\
\hline Tetric evoceram & 10 & 1.6300 & .61110 & .19325 & .80 & 2.80 & & \\
\hline $\begin{array}{l}\text { Admira fusion x- } \\
\text { tra }\end{array}$ & 10 & 2.6800 & .60700 & .19195 & 1.70 & 3.50 & & \\
\hline Total & 30 & 2.3133 & .76732 & .14009 & .80 & 3.60 & & \\
\hline
\end{tabular}

Table 5.The value of sig was 0.000 it is smaller than 0.01 , meaning there are statistically significant differences between the mean values between Average three material after one week.

Table no.5 Anova Test the contrast between the average read values of all materials at time week within Cola 


\begin{tabular}{|l|l|l|l|l|l|l|l|l|}
\hline & $\mathrm{N}$ & Mean & $\begin{array}{l}\text { Std. } \\
\text { Deviation }\end{array}$ & $\begin{array}{l}\text { Std. } \\
\text { Error }\end{array}$ & Minimum & Maximum & F & Sig. \\
\hline Tetric N-ceram & 10 & 9.6496 & 1.23600 & .39086 & 7.80 & 11.50 & 23.395 & $0.000^{* *}$ \\
\hline Tetric evoceram & 10 & 6.9096 & .63922 & .20214 & 6.00 & 8.00 & & \\
\hline $\begin{array}{l}\text { Admira fusion x- } \\
\text { tra }\end{array}$ & 10 & 7.9720 & .71481 & .22604 & 6.92 & 9.10 & & \\
\hline Total & 30 & 8.1771 & 1.44072 & .26304 & 6.00 & 11.50 & & \\
\hline
\end{tabular}

Table 6.The value of sig was 0.000 it is smaller than 0.01 , meaning there are statistically significant differences between the mean values between Average three material after 28 dayes.

Table no.6 Anova Test the contrast between the average read values of all materials at time 28 day within Cola

\begin{tabular}{|l|l|l|l|l|l|l|l|l|}
\hline & $\mathrm{N}$ & Mean & $\begin{array}{l}\text { Std. } \\
\text { Deviation }\end{array}$ & $\begin{array}{l}\text { Std. } \\
\text { Error }\end{array}$ & Minimum & Maximum & F & Sig. \\
\hline Tetric N-ceram & 10 & 15.1942 & 1.53740 & .48617 & 13.75 & 17.80 & 19.489 & $0.000^{* *}$ \\
\hline Tetric evoceram & 10 & 12.1892 & .70199 & .22199 & 11.20 & 13.40 & & \\
\hline $\begin{array}{l}\text { Admira fusion } \\
\text { x-tra }\end{array}$ & 10 & 13.2640 & .84411 & .26693 & 12.14 & 14.70 & & \\
\hline Total & 30 & 13.5491 & 1.64516 & .30036 & 11.20 & 17.80 & & \\
\hline
\end{tabular}

\section{Discussion}

Resin materials are important because they achieve similar appearance compared to natural teeth, But unfortunately These substances are likely to be discolored with long-term exposure to oral environment [15], The methodology used in the present study was in accordance with previous researches that used spectrophotometry and the CIE L*a*b* coordinate system, Most color determination studies in dentistry use the CIE L*a*b* system, and this system is almost exclusively based on color research in dentistry around the world. The color perception in the CIE system depends on the eye's sensation in three different colors (red, green, and blue). When the light reflects, it recieves and stimulates these receptors, and the result is sending three signals to the brain that determine whether the color is bright or dark red, green, yellow or blue. [16] After evaluating the color measurement process through direct vision and using digital devices, the amount of color change that can be observed when comparing teeth within the oral environment is determined by 3,7 according to the standards of the United States of Public Health Services (USPHS) [17]. this study was performed for a long-term staining protocol of 28 days because this time of exposure should simulate around 2 years of clinical exposure to the staining agents $(24 \mathrm{~h}$ in vitro corresponds to about 1 month in vivo), which is considered sufficient for a long-term staining susceptibility evaluation[15].In this study coffee presented a significant staining capacity regardless of the composite resin. The results of the present investigation showed significant differences in discoloration between the different groups. Several studies concerned with the staining of the restorations resulting from the colorants contained in the oxidizing pollutants, and the color changes of the resin restorations were evaluated after being immersed in various dyed liquids. Coffee, tea [18], red 
wine and soft drink, and fruit juices [18] The most common studied pigmentation factors. The pigmentation caused by these fluids varies according to composition and properties of the resin materials.[19]Reports have shown that both coffee and soft drinks caused a clear color change to the composite resin samples seven days after being immersed in solutions.[20] As shown in this study with $\Delta \mathrm{E}>3.3$ after week and 28 days but all materials showed acceptable values after 24 hours of immersed. From a clinical point of view, these factors that have a pronounced effect on the color stability of laboratory samples can also cause clinical color change, but the change in resin color will be clinically slower due to the continuous effect resulting from saliva and oral care procedures for patients. [21] The properties of the restoration surface have a significant effect on the color stability of the composite resin. Surface roughness is one of the causes of external pigmentation and is closely related to the size of the filling particles used and the finishing and polishing system used.[22] In this study no finishing or polishing were applied to the samples this might explain the high values of discoloration after week and 28 days as studies have reported that the restoration surface resulted from the use of polyester strips is exposed to the largest amount of color change, due to the fact that the outer layer of Restoration is hampered by its diffusion compared to the restoration mass. So removing this layer of resin during The finishing and polishing process will increase the staining resistance and thus achieve greater color stability for the restoration. [23] discoloration of the resin materials is due to internal and external reasons.[24] internal discoloration includes change in the color of the resin itself, such as the change of the resin matrix or filling material or the interface between them. Therefore, the structure of the resin matrix and the properties of the fillers has a clear influence on the color stability of the restoration[25] as well as the accelerators and inhibitors of the reaction[26]. As for the external pigmentation, it results from the absorption of colourants from the external environment. They differ according to the oral health of patients, as well as their food habits, drink and smoking.[27] Monomeers properties affect the color stability of the resin restorations, and most studies have shown that this is directly related to the hydrophilic and hydrophobic monomeers [28] and water absorption properties. [29] Water absorption has many harmful effects on the resin mold, as it causes it to swell due to moisture, entrainment and dissolution, or oxidation, and all of this leads to penetration of the pigmented factors within it in addition to the influence of its transparency.[30] The chemical composition of admira fusion x-tra is made of silicon oxide which forms both glass fillers and ceramic resin matrix that caused less water absorption and includes high color stability because It is synthesized through a solution and gelation process (solgel process) from multifunctional urethane and thioether(meth)acrylate alkoxysilanes. in addition to surface hardness and durability. .[30]The use of UDMA reduces the occurrence of pigmentation compared to the more common Bis-GMA .[31] Arikawa $\mathrm{H}$ et a 2007 showed that it is affected by the size and shape of the filling particles and the loading ratio.[18] Our results are in correspond with recent studies which reported higher discoloration for conventional nanohybrid to new nanohybrid ormocer ones.[32]

\section{Conclusion}

Within the limitations of this in vitro study, it can be concluded that the immersion of specimens in staining solution caused a significant color change in all types of tested composite resins. Coffee 
demonstrated a higher staining potential if compared to cola. Finally, among the different materials tested, nanohybrid ormocer composite ( Admira Fusion x-tra) reported the lowest color variations.

\section{Declarations}

\section{Acknowledgements:}

Not applicable.

\section{Ethical approval:}

This article does not contain any studies with human participants or animals performed by any of the authors.

\section{Funding:}

None.

\section{Availability of data and materials:}

The datasets used and/or analysed during the current study are available from the corresponding author on reasonable request.

\section{Consent for publication:}

Not applicable.

\section{Competing interests:}

The authors declare that they have no competing interests.

\section{References}

1. Paravina RD, Powers JM (2004). Esthetic Color Training In Dentistry. Saint Louis: Mosby P;(43-45).

2. Yew Z H Et Al .Colour Changes In Nano-Filled And Micro-Hybred Composite Resins On Exposure To Spices . The University Of Adelaide 2011. P;(30-32).

3. Mitchell Ch 2008 . Dental Materials In Operative Dentistry .5th Edition . P;(1-13),(100-106)

4. Marghalani HY (2010). Effect Of Filler Particles On Surface Roughness Of Experimental Composite Series. J Appl Oral Sci. Feb;18(1)P;(59-67).

5. Deligeorgi V,Mjor IA, Wilson NH. An Overview Of Reasons For The Placement And Replacement Of Restorations .Prim Dent Care 2001;8(1): 5-11

6. FERRACANE JL. Resine Composite-State Of The Art.DENT MATER.2011,27:29-38. 
7. MANHART J. Posterior Restoration With A New Nanohybridormocer Composite - A Clinical Case Report.Dentistry Journal,2016.P: 34-38.

8. SAHOO,S K; PARVEEN,S ; PANDA,J.J. The Present And Future Ofnanotechnology In Human Health Care.Nanomedicine $2007 ; 3$.

9. WILSON KS, ZHANG K, ANTONUCCI JM. Systematic Variation Of Interfacial Phase Reactivity In Dental Nanocomposites. 2005 Sep;26(25): 5095-5103.[Pubmed][Crossref].

10. MITRA SB, WU D, HOLMES BN. An Application Of Nanotechnology In Advanced Dental Materials. $J$ Am Dent Assoc. 2003 Oct;134(10):1382-1390.

11. WANG Y, LEE JJ, LLOYD IK, WILSON OC JR, ROSENBLUM M, THOMPSON V. High Modulus Nanopowder Reinforced Dimethacrylate Matrix Composites For Dental Cement Applications. $J$ Biomed Mater Res A. 2007 Sep;82(3):651-657.

12. TIAN M, GAO Y, LIU Y, LIAO Y, HEDIN NE, FONG H. Fabrication And Evaluation Of Bis-GMA/TEGDMA Dental Resins/Composites Containing Nanofibrillar Silicate. Dent Mater. 2008 Feb; 24(2):235-243.

13. XIA Y, ZHANG F, XIE H, GU N. Nanoparticle-Reinforcedresin-Based Dental Composites. J Dent. 2008 Jun;36(6):450-455.

14. GAROUSHI S, VALLITTU PK, WATTS DC, LASSILA LV. Effect Of Nanofiller Fractions And Temperature On Polymerization Shrinkage On Glass Fiber Reinforced Filling Material. Dent Mater.2008 May;24(5):606-610.

15. Matteo C, Matteo V, Davide R, Riccardo B, Marco C, Claudio P. Discoloration Of Different Esthetic Restorative Materials: A Spectrophotometric Evaluation.Brookings Dentist. 2017 | Volume: 11/ Issue : 2 . Page : 149-156/

16. Brook AH, Smith RN, Lath DJ. The Clinical Measurement Of Tooth Colour And Stain. Int Dent J. 2007;57:324-30. [Pubmed] [Google Scholar]

17. Lee YK, Powers JM. Discoloration Of Dental Resin Composites After Immersion In A Series Of Organic And Chemical Solutions. J Biomed Mater Res B Appl Biomater. 2005;73:3617. [Pubmed] [Google Scholar]

18. Arikawa H, Kanie T, Fujii K, Takashahi H, Ban S: Effect Of Filler Properties In Composite Resin On Light Transmittance Characteristics And Colour. Dent Mater J 2007 , 26(1)38-44

19. Marco Colombo, ${ }^{1}$ Lodovico Vialba, ${ }^{1}$ Riccardo Beltrami, ${ }^{1}$ Ricaldone Federico, ${ }^{1}$ Marco Chiesa, ${ }^{1}$ And Claudio Poggio Effect Of Different Finishing/Polishing Procedures On Surface Roughness Of Ormocer-Based And Different Resin Composites Dent Res J (Isfahan). 2018 Nov-Dec; 15(6): 404410.

20. RADZ GM. Direct Composite Resins, The Most Critical Improvments Have Come In The Filler Particles.INSIDE DENTISTRY,2015,7(7):108-114

21. Ertas E , Umut A, YÜCEL A, KÖPRÜLÜ H And GÜLER E . Color Stability Of Resin Composites After Immersion In Different Drink . Dental Materials Journal 25ه2ه囚371ه376, 2006. 
22. Carmen Llena Sarai Fernández Leopoldo Forner Color Stability Of Nanohybrid Resin-Based Composites, Ormocers And Compomers Clinical Oral Investigations May 2017, Volume 21, Issue 4, Pp 1071-1077 | Cite As

23. BARAKAH HM, TAHER N 2010. Effect Of Surface Polishing System On Color Stability Andnsurface Roughness Of Nano-Composite Resin Material. Collage Of Dentistry, King Saud University .P: (4-20) (26-30) .

24. Samara AP, Pereira SK, Delgado LC, Borges CP (2008). Color Stability Evaluation Of Aesthetic Restorative Materials. Braz Oral Res. Jul-Sep;22(3):205-10.

25. Mailart $M C^{1}$, Rocha RS ${ }^{1}$, Contreras $S C M^{1}$, Torres $C R G^{1}$, Borges $A B{ }^{1}$, Caneppele TMF Effects Of Artificial Staining On Bulk-Filled Resin Composites. ${ }^{1}$ American Journal Of Dentistry[01 Jun 2018, 31(3):144-148]

26. OMATA Y, UNO S, NAKAOKI Y, TANAKA T, SANO H, YOSHIDA S,Etal.Staining Of Hybrid Composites With Coffee,Oolong Tea, Or Red Wine.DENT MAT J.2006,25(1): 125-31.

27. CHADWICK, B; DUMMER, P; DUNSTAN, F. How Long Do Filling Last? Evid. Based Dent. 2002 ; 3:9699.

28. MANOJLOVIC, D ; LENHARDT, L; Milićević , B ; ANTONOV , B. Evaluation Of Staining-Dependent Colour Changes In Resin Composites Using Principal Component Analysis. Scientific Reports 5, Article Number: 14638 (2015) Doi:10.1038/Srep14638

29. DHURU, V. BENHAMUER, M. Water Sorption Of Selected Tooth Color Materials. J Dent Res. 2000 : 79:281.

30. ASMUSSEN, E; PEUTZFELDT, A. Influence Of UEDMA, Bisgma And TEGDMA On Selected Mechanical Properties Of Experimental Resin Composites. Dental Materials (1998) 14(1); 51 - 6.

31. TOMASZEWSKA IM, KEARNS JO, FLEMING GJP. Jornal Of Dentistry,2015.43: 309-316.

32. Lim YK, Lee YK, Lim BS, Rhee SH, Yang HCP: Influence Of Filler Distribution On The Colour Parameters Of Experimental Resin Composite . Dent Mater 2008, 24(10):67-71 . 